\title{
Update on Angiolytic Laser Laryngeal Surgery
}

\author{
Min Seok Kang ${ }^{1}$ (D) and Jae-Yol Lim² (D) \\ 'Department of Otorhinolaryngology, Korean Armed Forces Capital Hospital, Seongnam, Korea \\ 2Department of Otorhinolaryngology, Gangnam Severance Hospital, Yonsei University College of Medicine, Seoul, Korea
}

\section{혈관용해 레이저를 이용한 후두미세수술 최신 지견}

강민석 ${ }^{1}$, 임재열 2

${ }^{1}$ 국군수도병원 이비인후과, ${ }^{2}$ 연세대학교 의과대학 강남세브란스병원 이비인후과학교실

There are several lasers available for office-based or suspension microlaryngoscopy laser procedures in the treatment of laryngeal diseases. Each has advantages and disadvantages given the depth of penetration per unit of power, absorption in water, spectral absorption characteristics, mode of delivery, safety, and cost. It is important to note that while the proper selection of indication of treatment based on a laser wavelength is critical, of equal importance is selecting the appropriate power setting, focal length (or spot size), and time of exposure. The photoangiolytic lasers precisely target hemoglobin within the microcirculation of the highly vascularized tissue and may have better hemostatic effects and preservation of surrounding normal tissue than the $\mathrm{CO}_{2}$ laser. Although the choice of laser is purely theoretical and cannot be accurately concluded which parameters of laser (wattage and pulse width) were best to use, photoangiolytic laser surgery is safe and effective for specific laryngeal lesions. In this review, indications for photoangiolytic laser procedures for various laryngeal diseases, laser settings and surgical techniques for specific laryngeal lesions including sulcus vocalis, laryngeal dysplasia, and recurrent respiratory papillomatosis will be introduced. Pros and cons of in-office laser surgery using photoangiolytic laser and flexible $\mathrm{CO}_{2}$ laser will also be addressed.

Keywords Larynx; Vocal cords; Lasers; Leukoplakia.

\section{서 론}

음성수술에서도 레이저 수술의 안정성과 효과가 증명되면서, 다양한 종류의 후두 질 환에서 레이저 수술이 시행되고 있다. 최근에는 새로운 레이저 형태가 도입되면서 적용 분야가 확대되고 있다. 레이저 수술을 시행할 때, 좋은 치료 효과를 얻기 위해서는 질환 에 맞는 적절한 종류의 레이저를 선택하여야 하며, 이를 위해서는 레이저의 원리와 파장 에 따른 고유한 특성, 작동 방식 등에 대한 이해가 필요하다. 본 종설에서는 최근에 소개 된 혈관용해 레이저의 특성과 이를 바탕으로 어떠한 후두 질환 수술에 적용 가능한지 알아보고, 레이저 수술의 장점과 일차적인 치료 결과에 대해 기술하고자 한다.
Received June 15, 2021

Revised July 13, 2021

Accepted July 27, 2021

Corresponding Author Jae-Yol Lim, MD, PhD

Department of Otorhinolaryngology, Gangnam Severance Hospital, Yonsei University College of Medicine, 211 Eonju-ro, Gangnam-gu, Seoul 06273, Korea

Tel +82-2-2019-3460

Fax $+82-2-3463-4750$

E-mail jylimmd@yuhs.ac

ORCID iDs

Min Seok Kang (iD)

https://orcid.org/0000-0002-7147-900X Jae-Yol Lim (DD

https://orcid.org/0000-0002-9757-6414

This is an Open Access article distributed under the terms of the Creative Commons Attribution Non-Commercial License (https://creativecommons.org/ licenses/by-nc/4.0) which permits unrestricted non-commercial use, distribution, and reproduction in any medium, provided the original work is properly cited. 


\section{본 론}

\section{레이저의 원리와 특성}

레이저(light amplification by stimulated emission of radiation, laser)는 Gordon Gould가 1957년 처음 개발하였 으며, Maiman[1]이 1960년 ruby 레이저를 발견한 이후로 의 학 분야에서 활용되기 시작하였고, 1974년 Jako와 Strong이 레이저를 이용한 경구강 후두 수술(transoral laser microsurgery)을 처음 시행하였다. 먼저 레이저의 작동원리를 살펴 보면, 외부의 에너지가 레이저 매질(laser matrix)로 들어오면 서 흡수되면 흥분된 원자(atom)가 낮은 에너지 상태로 돌아가 며 광자(photon)가 자발적으로 방출되며(stimulated emission), 방출된 광자가 레이저 내부에서 계속 반사되어 다른 원 자들이 계속 광자를 방출하도록 하는 연쇄 반응(laser pumping)을 일으키면서 레이저 광원이 발생하게 된다[2,3].

레이저는 단색성(monochromaticity), 응집성(coherence), 평행성(collimation or directionality)의 세 가지 주요한 특성 을 가지고 있다. 이에 대해서 살펴보면 먼저 레이저는 단색 광 원(monochromatic light)으로 어떤 레이저 매질을 사용하는 지에 따라서 결정되는 빛의 파장이 다르며, 파장에 따라 다양 한 생체 기능을 갖는다. 또한 레이저 파장에 따라 조직 내 존 재하는 타겟 물질(색소, 혈관, 물, 지방 등)의 흡수 효율성 $(\mathrm{ab}-$ sorption efficiency)과 침투 깊이(penetration depth)가 달라 진다. 또한 레이저는 레이저 광원 내부에 존재하는 모든 광선 이 기타 모든 광선과 평행하게 주행하는 평행 광원(collimated light)이며, 일정한 공간을 같은 시간 내에 통과하는 응집 광원(coherent light)이다[4].

에너지 양의 단위는 Joules (J)로서, 이는 레이저의 강도(intensity, watts [W])에 레이저 광선이 전달된 시간(초, seconds) 을 곱하면 나오는 값이다(energy [J]=intensity [W]×time $[\mathrm{sec}])$. 레이저의 강도를 레이저가 전달된 면적 $\left(\mathrm{cm}^{2}\right)$ 으로 나눈 값을 power density 혹은 irradiance $\left(\mathrm{W} / \mathrm{cm}^{2}\right)$ 라고 하며, 이 값은 수술 부위에서 조직이 절제 혹은 제거되는 정도와 관련 이 있다. 또한 레이저 에너지가 전달된 면적 $\left(\mathrm{cm}^{2}\right)$ 으로 나눈 값 은 세기(fluence, $\mathrm{J} / \mathrm{cm}^{2}$ )라고 하며, 이러한 값은 주변 조직의 손상 정도와 연관이 있다[3].

레이저의 작동 방식은 동일한 크기의 에너지가 일정하게 방 출되는 continuous 방식과, 에너지 전달 시간을 쪼개서 반복 적으로 방출하는 pulsed 방식이 있다. Pulsed 방식은 다시 방 출되는 에너지의 양상에 따라 ultrapulse와 superpulse 방식 으로 나뉘고, pulse의 폭을 조정하여 long pulse 방식이나 short pulse 방식으로 다양하게 사용할 수 있다. Pulsed 방식 의 경우 continuous 방식에 비하여 단위면적당 전달 에너지의
세기가 크고 주변 조직으로 전달되는 열이 더 적기 때문에 주변 조직의 손상 정도가 더 작다[5]. Long pulse 조사 시에는 조직 내에 열을 가두는 thermal confinement가 우수하여 조 직 절제에 유리하나 주변 조직의 손상이 많아질 수 있고, short pulse는 조직 내 온도 상승이 $50 \%$ 이하로 감소하는 thermal relaxation time을 충분히 가져가기에는 유리하나 조 직 절제 시 오랜 시간이 소요되는 단점이 있기에 레이저 작동 방식을 수술 목적과 타겟 조직에 따라 적절히 조절하는 것이 필요하다.

\section{후두 질환의 레이저 수술}

이비인후과 영역에서 많이 사용되는 레이저로는 potassium titanyl phosphate laser (KTP, $532 \mathrm{~nm}$ ), pulsed dye laser (PDL, 585-600 nm), Nd:YAG laser (1064 nm), diode laser (375-3500 nm), $\mathrm{CO}_{2}$ laser $(10600 \mathrm{~nm})$ 등이 있다. 이 중에서 $\mathrm{CO}_{2}$ 레이저는 물에서 흡수가 잘되며, cutting/ablation에 유 리한 장점을 가지는 레이저로 현미경을 이용하여 작은 병변 을 정확하고 효과적으로 절제할 수 있고, 주변 조직에 손상을 비교적 적게 줄 수 있다는 장점 때문에 1970년대부터 많은 후 두 질환에 가장 표준적인 레이저 치료로 사용되어 왔다.

$\mathrm{PDL}$ 이나 KTP와 같은 레이저는 붉은 빛의 물질에서 흡수 가 잘되기 때문에 인체의 혈관 혹은 혈관이 풍부한 조직에 대 한 선택적인 광열분해(photothermolysis)가 잘 일어나는 특 성을 가지며, 따라서 이러한 레이저를 혈관용해 레이저(angiolytic laser)라고 부른다. 혈관용해 레이저는 상피는 보존하면 서, 상피 아래의 혈관층에 보다 더 선택적으로 작용하며, 주 변 정상 조직에 손상을 적게 일으키고, 지혈(hemostasis)이 잘 되는 특성을 바탕으로 다양한 후두질환에서 사용되어 왔다. 성대 혈관확장(vascular ectasia)이나 출혈성 성대 폴립(hemorrhagic vocal polyp), 재발성 호흡기성 유두종(recurrent respiratory papillomatosis) 등의 질환에서 가장 먼저 적용되었 다[6]. 우리나라에서는 $585 \mathrm{~nm}$ 의 PDL이 신의료기술로 인정되 었으나 이후 생산이 중단되면서, 동일 파장의 diode laser 대 신 $532 \mathrm{~nm}$ 의 KTP가 기존 기술로 허가되어 사용되고 있다.

재발성 호흡기성 유두종의 수술에 대하여 Siegel과 Smith [7]는 $\mathrm{CO}_{2}$ 레이저를 이용한 수술의 경우 주변 조직에 대한 열 손상으로 인하여 성대 협착(glottic stenosis), 피열연골 고정 (arytenoid fixation), 성대 섬유화(vocal fold fibrosis)와 같은 합병증이 잘 발생할 수 있다고 보고하였고, Holler 등[8]은 $\mathrm{CO}_{2}$ 레이저를 이용한 반복적인 수술의 경우 microdebrider 를 이용하였을 때보다 수술 후 음성의 상태가 더 좋지 않다는 단점을 보고하였다. 따라서 이러한 $\mathrm{CO}_{2}$ 레이저의 단점을 감 안하여 성대 전방 교차(anterior commissure), 혹은 후방 교 
차(posterior commissure)를 침범한 재발성 호흡기성 유두 종은 한쪽 방향씩 단계적인 수술을 하거나, 혹은 완전절제가 아닌 아전절제(sub-total debulking)를 시행하는 것이 권고 되었다[9].

최근 재발성 호흡기성 유두종에 대하여 좀 더 보존적인 치 료를 시행하기 위해서 혈관용해 레이저를 이용한 수술법이 주목받고 있다(Fig. 1). 혈관용해 레이저의 경우 Hartnick 등[10] 이 2007년에 시행한 연구에서 23명의 전방 교차를 침범한 소 아 재발성 호흡기성 유두종 환자를 대상으로 37 번의 $585 \mathrm{~nm}$ $\mathrm{PDL}$ 을 이용한 수술을 시행한 뒤 3 개월에서 1년간 추적관찰 을 했을 때, 수술 후 전방 교차 협착 소견을 보인 사례는 없 었다고 보고하였다. 혈관용해 레이저는 유두종과 주변 조직 의 미세 혈류를 차단하여 $\mathrm{CO}_{2}$ 레이저에 비해서 더 나은 지 혈 효과를 보이고 주변 조직의 손상을 더 적게 일으키며 굴곡 광섬유(flexible fiberoptics)를 통하여 레이저 에너지를 다양 한 방향에서 보다 더 용이하게 전달할 수 있는 장점 등을 가 지고 있기 때문이다. 비접촉 방식(noncontact mode)으로 소 작(vaporization)과 절제(ablation)가 모두 가능하나, 광범위 하게 퍼져 있는 병변을 제거할 때는 상대적으로 많은 시간이 소모될 수 있다는 단점이 있다.

\section{후두 레이저 수술의 새로운 적용 분야}

혈관용해 레이저는 앞서 언급했던 선택적인 광열분해 특성 을 이용한 혈관성 후두 질환에 대한 수술 외에도 다양한 후 두 질환에서 사용되고 있으며, 특히 성대 백반증(vocal fold leukoplakia) 및 성대암(vocal fold cancer)에 대한 레이저 수 술이 증가하고 있다. 성대 백반증은 임상적 용어로서, 떨어지 지 않는 백색판(wihte plaque) 부위를 뜻한다. 반면, 성대 각 화증(keratosis or hyperkeratosis)이나 이형성증(dysplasia) 의 경우 병리학적 용어이다. 각화증은 조직에서 비정상적인 상 피의 이상각화증(dyskeratosis) 소견을 보이지만 기저막(basal membrane)은 정상적이며, 비전형적 세포(cellular atypia) 소 견은 보이지 않는 경우를 뜻한다. 비정상적인 각화증과 비전
형적 세포 소견이 동반될 경우 이형성증으로 분류되며, 이형 성증은 전암성 병변(precancerous lesion)으로 간주된다. Isenberg 등[11]이 2008년 시행한 연구에 따르면 2188명의 후 두 백반증 환자의 $50 \%$ 는 양성 병변이었고, 나머지 $50 \%$ 가 전 암 병변이나 암 병변이었으며, 전암 병변인 이형성증 환자의 $8.2 \%$ 가 암 병변으로 전환될 수 있다고 발표하였다.

성대 백반증에 대한 수술은 이전에는 cold instrument를 이 용한 미세피판수술(microflap surgery), 혹은 $\mathrm{CO}_{2}$ 레이저를 이용한 미세절제술(microdissection) 등을 많이 시행하였으 나, 최근에는 혈관용해 레이저를 이용한 수술이 많이 시도되 고 있으며, 수술 범위에 따라 소작, 박피술(stripping), 절제술 (excision) 등의 기법을 사용할 수 있다. 그중에서 혈관용해 레 이저 박피술(angiolytic laser stripping)은 상피하 미세혈관 구조(subepithelial microvasculature)에 대한 선택적인 용해 (coagulation)를 통하여, 상피와 고유판의 표면(superficial lamina propria) 사이를 분리시켜 상피 부분의 성대 백반증 을 제거하는 수술 방법이다(Fig. 2). 혈관용해 레이저를 이용 한 성대 백반증 수술은 종양학적 결과에서 $\mathrm{CO}_{2}$ 레이저를 이 용한 수술과 차이를 보이지 않았으며, 음성 측면에서는 혈관 용해 레이저 수술 이전에 비하여 더 호전된 음성 결과를 보인 다고 보고되었다[12,13].

또한 성대구증에 대한 치료에서도 혈관용해 레이저가 사용 되고 있다. 성대구증은 고유판 표면의 소실 혹은 이상으로 성 대 표면에 홈이 파이는 질환으로, 이로 인하여 강직도가 증가 하고 성대 점막의 파동이 감소하며, 궁형 성대가 동반되어 발 성 장애를 일으키는 원인이 된다. 성대구증에 대한 치료는 단 순 거상술(simple elevation), 점막 절개술(pontes mucosal slicing), 절제 후 재위치(resection and reapproximation), 성 대 주입술(vocal fold injections), 자가 이식(autologous implantation), 혈관용해 레이저 성대성형술(angiolytic laser glottoplasty), 성장인자 주입술(growth factor therapy) 등의 다양한 치료가 있다[14].

이 중 혈관용해 레이저 성대성형술은 성대구증 부위에 혈
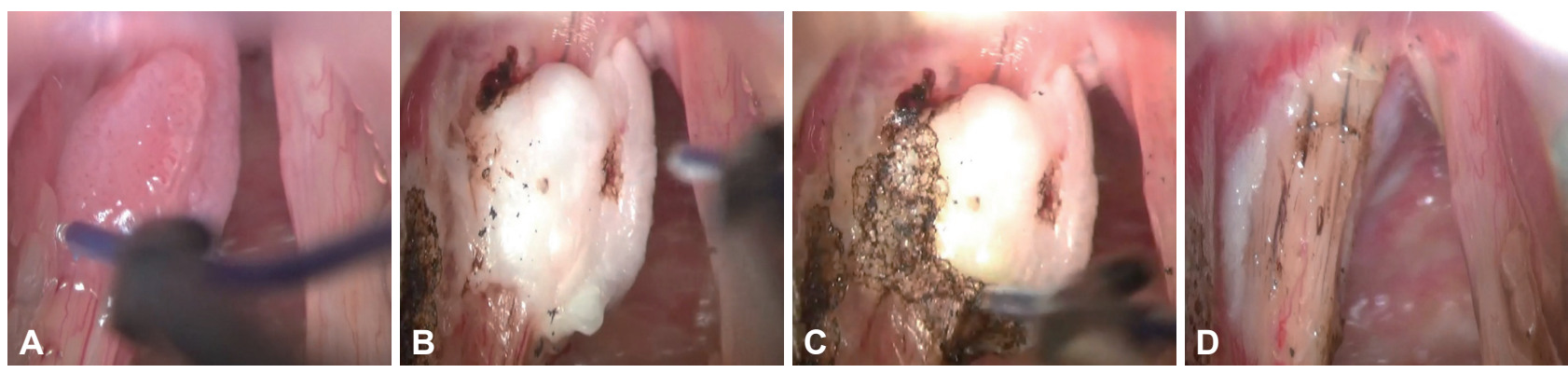

Fig. 1. Angiolytic laser surgical procedure for recurrent laryngeal papillomatosis. A: Preoperative photograph of laryngeal papillomatosis. B-D: Serial surgical photographs of angiolytic laser surgery. Laser was delivered by flexible fiber. Blanched papilloma lesions was removed by forceps. 

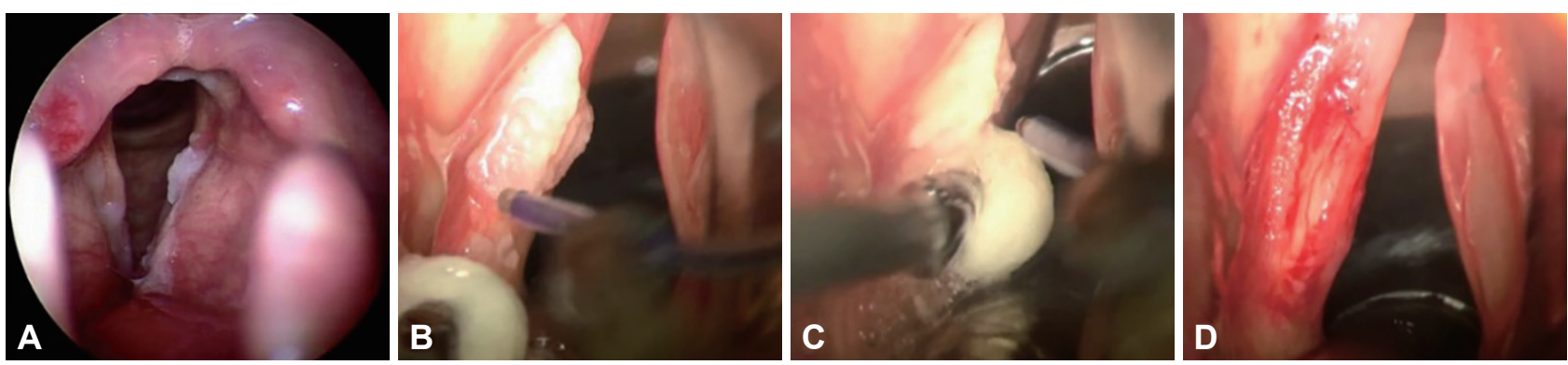

Fig. 2. Angiolytic laser surgerical procedure for vocal fold leukoplakia. A: Preoperative photograph of vocal fold leukoplakia. B-D: Serial surgical photographs of angiolytic laser stripping. After angiolytic laser was applied, leukoplakia lesion was stripped by cotton ball completely.
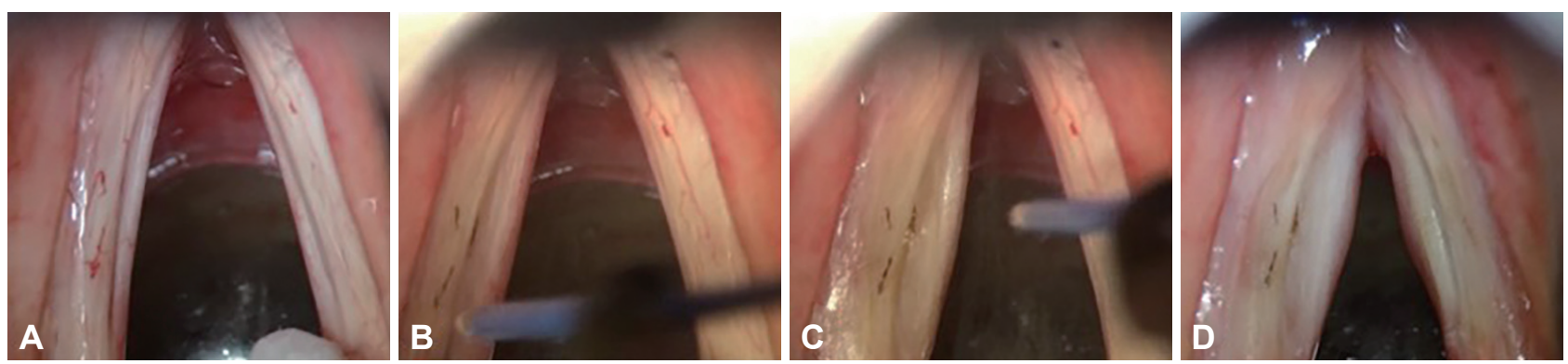

Fig. 3. Angiolytic laser surgical procedure for sulcus vocalis. A: Preoperative photograph of sulcus vocalis. B-D: Serial surgical photographs of angiolytic laser glottoplasty. Angiolytic laser was applied to sulcus lesions, then sulcus lesions were blanched and swollen.

관용해 레이저를 이용해서 scar remodeling을 유발하고 성 대 상피는 보존하면서 고유판의 표면 부위를 재건하는 수술이 다(Fig. 3). 성대구증에 대한 혈관용해 레이저 수술의 연구 결 과를 살펴보면, 먼저 생쥐를 이용한 동물 모델 연구에서 KTP (10 W, $20 \mathrm{msec}$ pulse width)를 생쥐의 후두에 조사하였을 때, 4주 후 대조군에 비하여 급성 염증 반응이 활성화되었고, 섬유화가 관찰되지 않는 결과를 보였으며, 이러한 반응이 scar remodeling 과정의 일부라고 보고하였다[15]. 또한 다른 연 구에서는 생쥐의 후두에 KTP를 $40 \mathrm{~W}, 50 \mathrm{msec}$ pulse width 로 조사하였을 때는 성대 점막에 손상이 발생하였으나 $10 \mathrm{~W}$, $20 \mathrm{msec}$ pulse width로 조사하였을 때는 점막이 회복된 것 을 확인하였다[16]. 또한 사람을 대상으로 한 연구 결과를 살 펴보면 2015년 Chang 등[17]이 시행한 연구에서 5명의 mucosal bridge를 동반한 성대구증 환자를 대상으로 PDL을 이 용하여 수술하였을 때 수술 후 유의미한 음성의 호전이 관찰 되었다고 보고하였다. 같은 그룹에서 2019년에 시행한 연구에 서는 총 79명의 성대구증 환자를 대상으로 혈관용해 레이저 성대성형술을 시행하였을 때 성대의 강직도가 감소하고 점막 파동이 증가하여 주관적인 설문 조사와 객관적인 음성 검사 모두에서 발성 장애가 호전되었다고 보고하였다[18].

\section{Office-based 레이저 수술}

혈관용해 레이저를 이용하여 외래에서도 성대 폴립, 성대 백반증, 재발성 호흡기성 유두종 등의 많은 질환에 대해서 수
술을 시행할 수 있다. 혈관용해 레이저의 경우 fiber-based 방 식이기 때문에 외래에서 시행하기에 적합하며, 진단과 치료를 동시에 진행할 수 있고, 전신 마취를 하지 못하는 경우에 awake 상태로 수술을 진행할 수 있어 비용이 더 적게 든다[19]. 2013 년 발표된 연구에서 혈관용해 레이저를 이용하여 21명의 재 발성 호흡기성 유두종 환자를 대상으로 총 81 회의 수술을 시 행하였을 때, 질병 상태의 유의미한 호전이 관찰되었으며, 음 성 설문 결과에서도 유의미한 호전이 관찰되었다[20]. 또한 2011년 발표된 다른 연구에서는 32명의 양성 성대 병변 환자 를 대상으로 47번의 혈관용해 레이저를 이용한 수술을 시행 하였을 때 성대 폴립이나 육아종 등의 양성 병변의 크기가 수 술전에 비하여 유의미하게 감소한 결과를 보였다[21]. 이러한 장점과 긍정적인 연구 결과들을 토대로 후두 질환에 대한 office-based 수술은 점점 더 적용범위를 넓혀 가고 있으며 수 술 시행 횟수 또한 늘어나고 있는 추세이다[22]. 특히 재발성 호흡기 유두종이나 성대 백반증과 같은 양측성, 재발성 병변 의 치료와 같은 반복적인 수술이 필요한 경우 장점이 있으며, 최근에는 적응증이 점차 확대되어서 성대 육아종(vocal fold granuloma)이나 일부 초기 성문암(early glottis cancer)에 적 용하기도 한다[19].

\section{결 론}

레이저는 매질과 구조에 따라서 방출되는 광선의 파장이 
다르며, 이로 인해 인체 조직 내 타겟 물질에 대한 침투 깊이와 흡수 정도가 달라진다. 이비인후과 후두 질환에서는 $\mathrm{CO}_{2}$ 레 이저나 혈관용해성 레이저 등이 많이 사용되고 있는데, 이 중 혈관용해성 레이저는 혈관 조직에 선택적으로 작용하여 높 은 지혈 효과를 보이고 주변 조직에 손상을 최소화할 수 있어, 출혈성 폴립, 재발성 호흡기성 유두종 등뿐만 아니라 성대구 증이나 성대 백반증 등 여러 후두 질환에서 사용이 가능하다. 또한 이러한 레이저는 굴곡 광섬유를 통하여 비교적 쉽게 후 두까지 접근할 수 있기 때문에, 필요에 따라 후두 양성 병변이 나 재발성 질환 등에 대해서 office-based를 용이하게 시행할 수 있다.

중심 단어: 후두; 성대; 레이저; 백반증.

\section{Acknowledgments}

None.

Conflicts of Interest

The authors have no financial conflicts of interest.

\section{Authors' Contribution}

Conceptualization: Jae-Yol Lim. Formal analysis: Jae-Yol Lim, Min Seok Kang. Investigation: Jae-Yol Lim, Min Seok Kang. Project administration: Jae-Yol Lim, Min Seok Kang. Supervision: Jae-Yol Lim. Visualization: Jae-Yol Lim, Min Seok Kang. Writing-original draft: Jae-Yol Lim, Min Seok Kang. Writing_review \& editing: Jae-Yol Lim.

\section{REFERENCES}

1. Maiman TH. Stimulated optical radiation in ruby. Nature $1960 ; 187$ : 493-4.

2. Fuller TA. Surgical lasers: A clinical guide. New York: Macmillan;1987. p.1-17.

3. Absten GT. Physics of light and lasers. Obstet Gynecol Clin North Am 1991;18(3):407-27.

4. Yan Y, Olszewski AE, Hoffman MR, Zhuang P, Ford CN, Dailey SH, et al. Use of lasers in laryngeal surgery. J Voice 2010;24(1):102-9.

5. Zeitels SM, Burns JA, Lopez-Guerra G, Anderson RR, Hillman RE. Photoangiolytic laser treatment of early glottic cancer: A new management strategy. Ann Otol Rhinol Laryngol 2008;117(7 Suppl):3-24.

6. McMillan K, Shapshay SM, McGilligan JA, Wang Z, Rebeiz EE. A 585-nanometer pulsed dye laser treatment of laryngeal papillomas: Preliminary report. Laryngoscope 1998;108(7):968-72.

7. Siegel B, Smith LP. Management of complex glottic stenosis in children with recurrent respiratory papillomatosis. Int J Pediatr Otorhi- nolaryngol 2013;77(10):1729-33.

8. Holler T, Allegro J, Chadha NK, Hawkes M, Harrison RV, Forte V, et al. Voice outcomes following repeated surgical resection of laryngeal papillomata in children. Otolaryngol Head Neck Surg 2009;141(4): 522-6.

9. Ivancic R, Iqbal H, deSilva B, Pan Q, Matrka L. Current and future management of recurrent respiratory papillomatosis. Laryngoscope Investig Otolaryngol 2018;3(1):22-34

10. Hartnick CJ, Boseley ME, Franco RA Jr, Cunningham MJ, Pransky S. Efficacy of treating children with anterior commissure and true vocal fold respiratory papilloma with the 585-nm pulsed-dye laser. Arch Otolaryngol Head Neck Surg 2007;133(2):127-30.

11. Isenberg JS, Crozier DL, Dailey SH. Institutional and comprehensive review of laryngeal leukoplakia. Ann Otol Rhinol Laryngol 2008; 117(1):74-9.

12. Park YM, Jo KH, Hong HJ, Choi HS. Phonatory outcome of $585 \mathrm{~nm} /$ pulsed-dye laser in the management of glottic leukoplakia. Auris $\mathrm{Na}-$ sus Larynx 2014;41(5):459-63.

13. Lim JY, Park YM, Kang M, Lee SJ, Baek K, Na J, et al. Angiolytic laser stripping versus $\mathrm{CO} 2$ laser microflap excision for vocal fold leukoplakia: Long-term disease control and voice outcomes. PLoS One 2018; 13(12):e0209691.

14. Soni RS, Dailey SH. Sulcus vocalis. Otolaryngol Clin North Am 2019; 52(4):735-43

15. Mallur PS, Branski RC, Amin MR. 532-nanometer potassium titanyl phosphate (KTP) laser-induced expression of selective matrix metalloproteinases (MMP) in the rat larynx. Laryngoscope 2011;121(2): 320-4.

16. Sheu M, Sridharan S, Paul B, Mallur P, Gandonu S, Bing R, et al. The utility of the potassium titanyl phosphate laser in modulating vocal fold scar in a rat model. Laryngoscope 2013;123(9):2189-94.

17. Chang JW, Park AY, Byeon HK, Choi HS. Use of pulsed dye laser treatments in patients with vocal fold mucosal bridges with sulcus vocalis - our experience of five cases. Clin Otolaryngol 2017;42(3): 715-9.

18. Park YM, Lim JY, Kang MS, Choi HS. Treatment outcomes of angiolytic laser-assisted glottoplasty in patients with sulcus vocalis. Ann Otol Rhinol Laryngol 2019;128(5):377-83.

19. Lee SW. Fiberoptic laryngeal laser surgery. J Korean Soc Laryngol Phoniatr Logop 2018;29(2):76-8.

20. Kuet ML, Pitman MJ. Photoangiolytic laser treatment of recurrent respiratory papillomatosis: A scaled assessment. J Voice 2013;27(1): 124-8.

21. Mallur PS, Tajudeen BA, Aaronson N, Branski RC, Amin MR. Quantification of benign lesion regression as a function of 532-nm pulsed potassium titanyl phosphate laser parameter selection. Laryngoscope 2011;121(3):590-5.

22. Tibbetts KM, Simpson CB. Office-based 532-nanometer pulsed potassium-titanyl-phosphate laser procedures in laryngology. Otolaryngol Clin North Am 2019;52(3):537-57. 